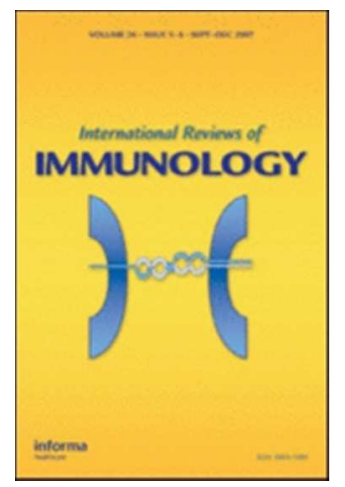

\title{
Targeting Tumor Initiating Cells through Inhibition of Cancer Testis Antigens and Notch Signaling: A Hypothesis
}

\begin{tabular}{|c|c|}
\hline Journal: & International Reviews of Immunology \\
\hline Manuscript ID: & GIRI-2015-0006 \\
\hline Manuscript Type: & Review \\
\hline Date Submitted by the Author: & 26-Jan-2015 \\
\hline Complete List of Authors: & $\begin{array}{l}\text { Colombo, Michela; Department of Health Sciences, University of Milan, } \\
\text { Mirandola, Leonardo; Texas Tech University, } \\
\text { Reidy, Adair; Texas Tech University, } \\
\text { Suvorava, Natallia; Texas Tech University, } \\
\text { Konala, Venu; Texas Tech University, } \\
\text { Chiaramonte, Raffaella; Department of Health Sciences, University of } \\
\text { Milan, } \\
\text { Grizzi, Fabio; Humanitas Clinical and Research Center, } \\
\text { Rahman, Rakhshanda; Texas Tech University Health Sciences } \\
\text { Center, Amarillo Breast Center of Excellence, TX, USA, } \\
\text { Jenkins, Marjorie; Texas Tech University, ; Laura W. Bush Institute for } \\
\text { Women's Health and Center for Women's Health, } \\
\text { Nugyen, Diane; Kiromic, LLC, } \\
\text { Dalhbeck, Scott; Texas Tech University, } \\
\text { Cobos, Everardo; Texas Tech University, ; Kiromic, LLC, } \\
\text { A Figueroa, Jose; Texas Tech University, ; Kiromic, LLC, } \\
\text { Chiriva Internati, Maurizio; Texas Tech University, ; }\end{array}$ \\
\hline Keywords: & $\begin{array}{l}\text { Notch signaling, Cancer testis antigens, cancer stem cells, tumor initiating } \\
\text { cells }\end{array}$ \\
\hline
\end{tabular}

\section{SCHOLARONE ${ }^{\text {Tx }}$}

Manuscripts 


\section{Targeting Tumor Initiating Cells through Inhibition of Cancer Testis Antigens and Notch Signaling: A Hypothesis}

Michela Colombo ${ }^{1,2}$, Leonardo Mirandola ${ }^{2,3,4}$, Adair Reidy $^{2,4}$, Natallia Suvorava ${ }^{2}$, Venu

Konala $^{2}$, Raffaella Chiaramonte ${ }^{1}$, Fabio Grizzi ${ }^{5}$, Rakhshanda Layeequr Rahman ${ }^{6}$, Marjorie R. Jenkins ${ }^{3}$, Diane D. Nugyen ${ }^{4}$, Scott Dalhbeck ${ }^{2,4}$, Everardo Cobos ${ }^{2,4^{*}}$, Jose A.

Figueroa $^{2,4^{*}}$, Maurizio Chiriva-Internati ${ }^{2,3,4^{*}}$

${ }^{1}$ Department of Health Sciences, University of Milan, Italy.

${ }^{2}$ Division of Hematology and Oncology, Texas Tech University Health Sciences Centre, Lubbock, Texas, USA.

${ }^{3}$ The Laura W. Bush Institute for Women's Health and Center for Women's Health and Gender-Based Medicine, Texas Tech University Health Sciences Center, Amarillo, Texas, USA.

${ }^{4}$ Kiromic, LLC, Lubbock, Texas, USA.

${ }^{5}$ Humanitas Clinical and Research Center, Milan, Italy.

${ }^{6}$ Division of Surgical Oncology, Texas Tech University Medical Center, Amarillo, TX, USA.

*Equal contribution senior authors

Running head: Tumor initiating cells, CTA and Notch

\section{Corresponding Author:}

Maurizio Chiriva-Internati, D.B.Sc, P.h.D.,

Division of Hematology \& Oncology

Department of Internal Medicine

Texas Tech University Health Sciences Center 3601 4th St., Mail Stop 9410

Lubbock, TX, 79430, USA

Lab: 806-743-3155 ext 279,280

Office: $\quad+18067432030$ ext 239 
$\begin{array}{ll}\text { Cell: } & +18062525845 \\ \text { Fax: } & +18067433148 \\ \text { E-mail: } & \quad \text { maurizio.chiriva@ttuhsc.edu }\end{array}$

Acknowledgment: this work was supported by the Associate Dean for Oncology Programs at TTUHSC, The Billy and Ruby Power Endowment for Cancer Research, The Laura W Bush Institute for Women's Health, Kiromic, LLC and Endowed Chair for Excellence in Women's Health Director of Breast Health Service.

\section{Abstract}

Tumor initiating cells (TICs) differ from normal stem cells (SCs) in their ability to initiate tumorigenesis, invasive growth, metastasis and the acquisition of chemo and/or radio-resistance. In the last years, several studies have indicated the potential role of the Notch system as a key regulator of cellular stemness and tumor development. Furthermore, the expression of cancer testis antigens (CTA) in TICs, and their role in SC differentiation and biology, has become an important area of investigation. Here we propose a model in which CTA expression and Notch signaling interacts to maintain the sustainability of self-replicating tumor populations, ultimately leading to the development of metastasis, drug resistance, and cancer progression. We hypothesize that Notch-CTA interactions in TICs offer a novel opportunity for meaningful therapeutic interventions in cancer. 
Keywords: Notch signaling, Cancer testis antigens, cancer, stem cells

\section{Tumor initiating cells: the dark side of stemness}

Stem cells (SCs) are toti-potential cells capable of an unlimited number of replication cycles and, under appropriate stimuli, differentiation into more specialized cells. This basal cell compartment constitutes the internal repair and self-renewal system in normal tissues. It is this balance between cellular self-renewal and differentiation what maintains normal tissue architecture and function. Therefore, it is not surprising that molecular derangements that affect this highly regulated process can lead to uncontrolled cellular growth, aberrant differentiation and tumor development.

The proposed existence of a population of tumor initiating cells (TIC) that mediate tumorigenesis and cancer progression has forced us to revisit our understanding of the fundamental processes governing cancer development. Unlike normal SCs, TICs have lost their stringent regulation and display a tendency for tumorigenesis, cellular invasiveness and metastatic potential [1]. The renewed interest in the study of TIC biology stems from the fact that their identification and therapeutic targeting may result, not only on improved tumor responses, but also in the potential eradication of neoplastic cells associated with pharmacologic resistance and disease relapse.

Several hypotheses have been proposed to account for the origin and development of TICs. The stochastic model suggests that normally differentiated cells can acquire a transformed phenotype capable of driving tumorigenesis through clonal evolution. Alternatively, the hierarchic model proposes that normal SCs may undergo an oncogenic event and subsequently serve as a continuous source of neoplastic cells, intrinsically resistant to standard therapeutic interventions. These two views are not necessarily mutually exclusive and a combined model may account for tumor development and progression, more accurately [2]. For example, TICs may originate either from normal SCs or more differentiated progenitors that acquire the capacity for self-renewal, invasive 
behavior and metastatic potential. Brabletz et al. has proposed the concept of "migrating TICs" (mTICs) which possess both stemness and migratory capabilities associated with the acquisition of epithelial-mesenchymal transition (EMT) phenotype [3]. This switch from SCs to mTICs appears to relate, not only to genetic alterations, but also to microenvironmental factors. These permissive micro-environmental niches may promote TIC proliferation and differentiation into invasive and metastatic cell populations, resulting in tumor progression and the emergence of resistance to standard treatments.

TICs are usually characterized by the expression and/or deregulation of genes involved in embryonic development, such as the Hedgehog, Notch and Wnt signaling pathways. These three signaling pathways appear to be fundamental in TIC biology and represent promising targets for therapeutic intervention [4]. In the next sections we will discuss the role of the Notch signaling pathway in cellular stemness and tumorigenesis, as well as its interaction with the family of proteins known as cancer testis antigens (CTAs), recently found to be expressed on TICs [5].

\section{The Notch pathway}

The Notch family of proteins includes a total of four highly homologous receptors (Notch-1, Notch-2, Notch-3, Notch-4) with important roles in the regulation of various processes, including neurogenesis, gliogenesis, myogenesis, vasculogenesis, hematopoiesis and epidermal development [6]. The Notch system is involved in the homeostasis of adult tissues by promoting self-renewal of SCs, determining cell fate (such as commitment towards $\mathrm{T}$ or $\mathrm{B}$ cell lineage) and regulating the differentiation of many cell types. Because of its extensive involvement in all these processes, mutations and/or deregulation of Notch receptors and/or ligands has been associated with the genesis of various malignancies [7]. Notch signaling depends on its interaction with specific ligands, proteolytic cleavage, release of Notch's cytoplasmic portion and subsequent translocation to the nucleus [8]. In vertebrates, two closely related families of ligands are capable of interacting with Notch receptors: the Delta-like (DLL-1, -3, -4 and DLL-2, described only in Xenopus) and the Serrate-like (Jagged1 and 2) ligands [9]. Notch signaling is dependent on cell-to-cell communication and is activated when Notch ligands, present on the "sending cell", bind to Notch receptor on the "receiving cell". Ligand binding triggers conformational changes in Notch receptors that allow access to the ADAM/TACE (A disintegrin and metalloprotease/tumor-necrosis-factor a converting enzyme) metalloprotease. The resulting proteolytic cleavage occurs within the extracellular domain 
(approximately 12 amino acids proximal to the transmembrane domain), at a site referred to as the $\mathrm{S} 2$ cleavage site [8]. ADAM/TACE leaves a short-lived fragment anchored to the plasma membrane, known as Notch extracellular truncation (NEXT), which is then recognized by the inactive aminopeptidase domain of Nicastrin (NCT) and transferred to the active site of the enzyme $y$-secretase. $Y$-secretase operates within the transmembrane domain (between site S3, near the inner plasma membrane, and site S4, near the middle of the transmembrane domain) and releases the Notch intracellular domain (NICD) whiche then translocates to the nucleus (or endoplasmic reticulum), and interacts with the DNAbinding protein complex CBF-1/RBP-Jk (Cp-binding factor-1/(Recombination signal sequence-binding protein $\mathrm{Jk}$ ) to regulate transcription of Notch-dependent genes $[9,10]$.

NICD transcriptional targets include Hairy/Enhancer of Split (HES) genes, HES-related repressor protein (HERP), class $\mathrm{C}$ bHLH (basic-helix-loop-helix) proteins acting as transcriptional repressors of tissue-specific genes (such as MASH-1 in neurogenesis, MyoD in myogenesis and E2A in B lymphopoiesis), the pre-TCR alpha (which participates in regulating the $T$ cell progenitors differentiation), cell cycle regulatory genes such as cyclin D2, cyclin D1, p21 and p27, and genes from different chemokine systems $[11,12,13]$.

Notch signaling is involved in the regulation of SC fate, in both embryonic and adult tissues. Activation of the Notch pathway has been shown to regulate the transit of nervous SCs from quiescence to a proliferative state and, together with Wnt signaling, also coordinates proliferation and differentiation of intestinal SCs [14]. Since deregulation of the Notch system has been shown to be involved in the patho-biology of many neoplasms, it is not surprising this signaling pathway is of fundamental importance in the molecular processes involved in TIC development.

\section{Notch and TICs}

Activation of the Notch system promotes self-renewal of TICs in several malignancies and participates in the interactions between tumor cells and the microenvironment, in both primary and metastatic neoplasms [15]. The Notch signaling pathway regulates not only the formation of TICs, but also their acquisition of the EMT phenotype which promotes metastasis and drug resistance [16]. Notch signaling has been demonstrated to be crucial in neural SCs biology based on its ability to inhibit neuronal differentiation [17]. The observation that Notch activation up-regulates AKT and MCL-1 expression in glioma SCs after radiation, indicates its importance in mediating resistance 
to DNA damage-induced apoptosis [18]. Glioblastoma multiforme (GBM) SCs appear to be sensitive to Notch-inhibitors, reflecting the importance of Notch and HES gene family activation in their biology. A study by Shiras et al. demonstrated that Notch blockade can reduce the CD133-positive SC fraction and abolished the non SC population in a human model of GBM, suggesting this pathway is involved in maintenance of the TIC compartment and tumorigenesis [19]. Notch and Wnt pathways also play crucial roles in coordinating proliferation and differentiation of intestinal stem cells in mice [14], and their activation leads to amplification of the intestinal SC/progenitor cell pool and inhibition of cell differentiation [20]. The importance of Notch signaling in gastrointestinal tissues is further supported buy its association with chemotherapy resistance in gastric tumors [21] and up-regulation of Notch1 and HES1 in colon adenocarcinomas, compared to normally differentiated colonic cells [22]. Since maintenance of undifferentiated, proliferative cells in intestinal crypts and adenomas requires activation of the Notch pathway, inhibition of Notch signaling by $\mathrm{Y}$-secretase inhibitors has been proposed as a treatment for colorectal cancer [23].

The Notch pathway is also deregulated in breast cancer (BC) and its activation may protect BCs from drug-induced apoptosis [24, 25]. Indeed, Notch signaling has been suggested as one of the conserved developmental pathways leading to TIC maintenance and resistance to conventional chemotherapy in this disease [26]. In ovarian cancer (OC) Notch3 activation has been associated with chemo-resistance and poor prognosis $[27,28]$. McAuliffe et al. have demonstrated over-expression of Notch3 in OC is associated with an increased TIC population and development of resistance to cisplatin, while Notch3 inhibition results in reduction of TICs and restoration of sensitivity to platinum agents [29]. Aberrations in Notch signaling have also been linked to several hematological malignancies, including T-cell acute lymphoblastic leukemia (T-ALL), acute myeloid leukemia (AML), lymphoma and multiple myeloma (MM) [6, 12]. The role of Notch signaling in hematopoiesis and in hematopoietic SC (HSC) development and maintenance has been extensively reviewed by Bigas and Espinosa [30], the fundamental finding being that activation of the Notch pathway is necessary for HSCs maintenance, and its inhibition results in HSCs differentiation and depletion [31]. The role of Notch signaling in the biology of leukemic SCs (LSCs), however, appears to be context-dependent and requires further study before its importance is completely understood in these diseases [31].

\section{Cancer Testis Antigens}


Cancer Testis Antigens (CTA) are a sub-class of tumor associated antigens first cloned by van der Bruggen et al. in 1991 [32]. CTA expression is mainly restricted to the testis and neoplastic cells of various histological origins, with the vast majority of these molecules having negligible or no expression in normal somatic cells [33-43]. This restricted expression pattern depends on methylation of upstream control elements and can be altered by DNA methyl-transferase-1 inhibitors, such as 5-aza-2-deoxycytidine, and histone deacetylase (HDAC) inhibitors [44]. Since cancer is characterized by global genomic hypomethylation, $\mathrm{CpG}$ island hypomethylation is likely to represent a major mechanism for re-activation of CTA transcriptional expression in cancer. Simpson et al. have recently suggested that CTA expression in cancer cells may be the result of reactivation of a gametogenic program as part of the process of neoplastic transformation [45]. Indeed, a number of CTAs normally expressed at various stages of gametogenesis have also been found in cancer cells, suggesting the triggering event is re-activation of a germ cell developmental program [45]. This theory supports the recent observation that some CTAs are expressed in TICs, cells characterized by self-renewal abilities similar to germ cells.

The possibility that CTAs may be expressed by TICs suggests these molecules may also serve as therapeutic targets. TIC-specific interventions, such as vaccines and/or other immunotherapeutic approaches targeting CTAs, may result in eradication of this selfrenewal cell population and increased cure rates in specific malignancies. In fact, their restricted tissue expression, high immunogenicity and presence of HLA-I-restricted epitopes, make CTAs ideal candidates for the immunotherapeutic targeting of cancer [36, $46,47]$. So far, most CTA-specific vaccines have targeted CTAs such as MAGE-A, NYESO-1, and SSX, with variable success [48, 49]. More recently, a novel group of CTAs belonging to the sub-group of scaffolding sperm proteins, namely SP17, AKAP-4 and Ropporin-1, have shown promise as targets for immunotherapeutic interventions in certain malignancies [33, 36, 40, 41, 50-52]. Among these, only SP17 has been evaluated in the clinical setting [53]. In this study, SP17-loaded autologous dendritic cells (DCs) were used to treat a MM patient, who had developed disease progression, and resulted in SP17specific immunity and reduction of serum paraprotein levels [53]. Based on these preliminary results, evaluation of this CTA sub-group of scaffolding sperm proteins is clearly warranted in a larger group of MM patients. More importantly, further studies to unravel the link between CTA expression and TIC biology are necessary in order to develop effective TIC-targeted therapies in the future. 


\section{CTAs as markers of tumor stemness}

The expression of CTAs by TICs, and the functional relation between CTAs and cell stemness, has become an active area of research. It has been suggested that CTA expression may play a role in SC differentiation pathways and embryonic development.

For example, during embryonic development the epiblast gives rise to mesenchymal SCs (MSCs) and primordial germ cells with active CTA expression programs [54]. Differentiation of these primordial cells results in down-regulation of CTA expression and may explain why CTAs are not detected in spermatocytes or oocytes, but are present in gametagonia [54]. In addition to other processes associated with SCs, such as the level of histone acetylation and lack of cellular differentiation, CTAs may serve as markers of stemness in specific neoplasms. The role of CTAs as SC markers is supported by the detection of CTA expression in bone marrow MSCs. Expression of CTAs, such as NYESO-1, MAGE1, SSX and N-RAGE, has been shown to be down-regulated in adipocytes and osteocytes after their complete differentiation from MSCs [55]. CTA expression may also confer a functional advantage to cancer cells by modulating their invasive and metastatic potential. For example, SSX down-regulation in melanoma cells results in decreased expression of matrix metalloprotease-2 (MMP2) and migration potential [56]. Since the process of malignant transformation may be defined by mutational deregulation of SC programs for self-renewal and differentiation, CTA expression may serve, not only as a potential marker of tumor cell stemness, but as an attractive target for treatment of TIC-dependent metastatic, recurrent and/or resistant disease [57].

Expression of CTAs in tumor SCs or TICs has been evaluated in several tumor models. GBM is a primary glial malignancy believed to have a defined SC population [58]. CD133 expression has been suggested as a marker of stemness in this malignancy based on the observation that CD133 positive cells can give rise to tumorigenic cells $[58,59]$. Interestingly, CTAs such as LAGE-1, NY-ESO-1 and MAGE family members are also expressed in GBM CD133 positive cells, compared with differentiated or parent cells [59]. Moreover, the expression of MAGE family members and CD133 is down-regulated as cells become more differentiated, indicating a correlation between expression of these molecules and the undifferentiated cellular state [59]. Since CD133 negative GBM cells can also be tumorigenic [58], CD133 expression can't be considered a specific marker for GBM stemness. Therefore, determination of expression of certain CTA expression patterns could be helpful in determining cellular stemness among CD133 negative GBM 
cell populations. Studies with MM clonogenic precursors (CD138 negative B cells thought to be MM SCs) have also revealed expression of MAGE A3/A6 and MAGE-C1/C7, as well as the protective role these CTAs confer against apoptosis [60]. MSCs can also give rise to TICs with specific neoplastic characteristics and it has been suggested these TICs comprise the main cellular compartment expressing CTAs within a given tumor [56, 57]. Gjerstorff et al. have found high levels of expression of several CTAs, such as CAGE, MAGE-A and XAGE-1, in tumorigenic MSCs, as opposed to primary human MSCs [57]. These observations support the notion that CTA expression may be associated with neoplastic transformation of normal SCs. Since promoter hypomethyation is one of the main regulatory mechanisms involved in CTA expression, changes on CTA-specific epigenetic control mechanisms may help differentiate neoplastic (i.e., TIC) from normal SCs. This distinction is important since it could have both therapeutic and prognostic implications.

\section{Interactions between Notch signaling and CTA expression in TICs: Lessons from MM.}

The discovery of embryonic, germinal and tumor-restricted expression of CTAs has advanced the hypothesis of a functional correlation between embryogenesis, gametogenesis, and tumorigenesis [61,62]. These observations have partially resurrected John Beard's "Trophoblastic Theory of Cancer" proposing that all tumors carry a population of cells with germ-like features originating from germinal cells which have failed to migrate to the gonads [63]. Thus, aberrant CTA expression in tumors may reflect reactivation of a gametogenic program involved in maintenance of stemness in specific cellular compartments, such as TICs [62]. As previously discussed, there is evidence supporting the hypothesis that the Notch pathway may also be associated with reactivation of a germinal cell transcription program in TICs. Since Notch signaling is an important regulator of germ cell development, it is likely that the common expression pattern shared by Notch1 and CTAs in germ cells [14-18] reflects a biologically relevant interaction between these two pathways.

Several CTAs are expressed in MM cells and their expression appears to play an important role in cell proliferation and resistance to apoptosis [60, 64-67]. Our group was the first to identify expression of two novel CTAs, AKAP-4 and SP17, in more than $75 \%$ of MM cell lines and patients [37]. Jungbluth et al. have reported expression of MAGE-C1 and MAGE-A3/6 in MM, their expression correlating with MM cell proliferation [68]. CTA 
expression in MM appears to occur early in the evolution of this disease and maintained thorough clinical progression, suggesting CTA expression may confer a selective advantage to MM neoplastic cells [69]. CTA expression in malignant MM cells has also been correlated with the activation of Notch signaling through the Jagged-2 ligand [70]. Moreover, activation of Notch signaling has been associated with drug resistance, as well as cross-talk between MM cells and bone marrow microenvironment [71,72], the latter being a critical requirement for maintenance of MM SC population [67].

In vitro and in vivo studies support a "compartmental model" for MM. In this model two cellular compartments exist: 1. a small, proliferating fraction of self-renewing progenitor cells (the so called MM SC); 2. a non-proliferating compartment exhibiting plasma cell differentiation and resistance to apoptosis [73]. Here, we propose a different model in which Notch signaling and CTA expression interact to maintain a self-replicating MM cell population. Although CTA expression has been described in a broad range of solid and hematologic malignancies [33,35,36,39,40,41,43], MM is distinct in that a significant majority of patients express AKAP-4 and/or SP17 in their tumor cells $[34,37,38$, 42]. No other type of cancer has such a close association with specific CTA expression pattern. To date, the molecular and biological actions of SP17 and AKAP4 are incompletely understood. Nonetheless, several reports have implicated SP17 in cell-to-cell adhesion and/or cell migration of lympho-hematopoeitic cells, possibly through its heparan sulphate binding domain [74]. SP17 has two additional functional domains, an N-terminal domain highly conserved among mammals and $45 \%$ identical to the type II alpha regulatory subunit of protein kinase $A$ (RII-PKA) and a C-terminal calmodulin binding domain $[75,76]$. AKAPs represent a family of proteins characterized by their ability to bind and regulate PKA function by localizing this critical enzyme to specific sub-cellular compartments. Its structural homology to a PKA regulatory subunit suggests a potential role for SP17 in signal transduction. In fact, non-PKA proteins containing an RII-PKA-like domain at their N-terminal, such as Sp17, can interact with AKAPs via hydrophobic residues [75]. For example, Lea et al. have demonstrated SP17 can bind the RII-PKA binding site of AKAP3, the most abundant AKAPs in the fibrous sheath of mouse flagella of spermatozoa [77]. This finding suggests a mechanism by which SP17 may regulate PKA-dependent processes. By physically interacting with AKAPs RII-PKA binding site, SP17 may disrupt the primary interaction of between AKAPs and PKA, resulting in mislocalization of PKA and interference with its activity at specific subcellular compartments, as well as modulation of other critical signal transduction pathways related to PKA 
activation. Alternatively, and by virtue of AKAP-specific anchoring to subcellular locations, AKAP-bound SP17 may be translocated to specific compartments where it may exert, as of yet, unknown biological functions.

Activation of AKAP proteins can also occur under a variety of stimuli leading to increase intracellular cAMP levels and consequent PKA activation [78]. Interestingly, a role for PKA signaling in Notch activation has been clearly demonstrated by Weber and colleagues [79]. The investigators showed that treatment of osteoclasts with parathyroid hormone (PTH) induces a cAMP/PKA-dependent 8-fold increase in Jagged1 expression. This finding is particularly relevant since Jagged1-mediated Notch activation has been shown to drive proliferation of MM cells [70]. Another clue pointing to a role of PKA signaling in Notch activation has been provided by a study by Yurugi-Kobayashi and colleagues showing that cAMP-dependent PKA activation leads to suppression of COUPTFII expression, up-regulation of NRP1, and consequent Notch activation, in vascular progenitor cells [80]. These findings indicate a possible role for SP17 and/or AKAP-4dependent PKA activation in the regulation of Notch ligand expression (Figure 1). Therefore, coordination of SP17/AKAP4 expression and Notch signaling may result in enhanced self-renewal and survival abilities of MM TIC compartment. Taken together, these data suggest SP17 may play a regulatory role in the activation of important signal transduction pathways by modulating the interaction between PKA and AKAPs. SP17 could also participate, through its Rll-like N-terminal domain and the central heparan sulphate binding domain, in key developmental processes such as cell migration and Hedgehog signal transduction [81-83].

\section{Future perspectives: immunotherapeutic implications}

Cancer vaccines represent the most advanced immunotherapeutic approach for oncologic patients. Classically, cancer vaccines are designed to exploit tumor targets derived from cancer-inducing infectious agents and/or tumor-associated antigens. We believe CTAs represent ideal cancer antigenic targets based on their selective expression in immune privileged sites (i.e., testes) and neoplasms, but not in normal cells. Moreover, the expression of CTAs by TICs, represent a powerful target for immunotherapeutic interventions that may eradicate this fundamental and aberrant cellular compartment responsible for initiation and maintenance of the neoplastic clone. With the discovery of TIC-associated CTA expression the possibility of improving disease-free survival and cure rates in cancer patients may become a reality. The efficacy of TIC-targeting vaccines has 
been explore with some success in acute myeloid leukemia (AML) [84]. However, the lack of AML-TIC-restricted targets raises concerns about potential toxicities, which in principle could be minimized by targeting TIC-associated CTAs [85].

It is evident that any strategy designed to increase expression of cancer-restricted antigens would result in better responses to cancer vaccine strategies [86]. Regulation of CTA expression in tumors of different histological origin is based on epigenetic tuning of promoter availability and chromatin remodeling [87-90]. Notch signaling has been shown to down-regulate the expression of specific targets by increasing promoter methylation in genes such as $\mathrm{pRb}$ and vascular endothelial growth factor receptor (VEGFR)-2 [91]. Therefore, the possibility exists that Notch signaling may contribute to mitigate the expression of CTAs in selected tumoral sub-populations, such as TICs. In this scenario, Notch-inhibiting agents, in combination with CTA-targeting vaccines, would improve therapeutic efficacy by increasing the probability of TIC eradication. Additionally, inhibition of Notch signaling by itself is expected to reduce the self-renewal ability of TICs, which would then make these cells more susceptible to CTA-specific cytotoxic lymphocyte killing. The potential drawback of this approach, however, would be the lack of tumor specificity of Notch targeting, compared with CTA targeting. Currently, the only strategy tested in patients to inhibit Notch signaling is the use $y$-secretase inhibitors, which results in serious gastrointestinal toxicity due to induction of intestinal metaplasia, a consequence of deregulation of goblet cell differentiation in the intestine [92,93]. Intestinal metaplasia is caused by the concurrent inhibition of both Notch1 and 2, indicating independent targeting of Notch1 or Notch2 specific antibodies may eliminate the observed toxicity, as demonstrated animal models of acute leukemias [94]. The use of antibodies that specifically block tumor-associated Notch isoforms, and/or their ligands, represent a potential alternative to toxic demethylating agents, such as 5-aza-2'-deoxycytidine, and ysecretase inhibitors [95]. As discussed above, selective Notch blockade would result in increased CTA expression by TICs making these more susceptible to the cytotoxic effects of therapeutic cancer vaccines. To date, several clinical trials are evaluating the safety and efficacy of Notch inhibition in both solid and hematological malignancies, including MM (www.clinicaltrials.gov). These studies should provide the necessary information to design future clinical trials combining Notch inhibition and CTA overexpression and immunotargeting for the treatment of selective cancers $[86,95,96]$. 


\section{Declaration of Interest Statement}

The authors have no conflict of interest to disclose.

\section{References}

1. Dean M. Cancer stem cells: Implications for cancer causation and therapy resistance. Discov Med. 2005;5:278-82.

2. Campbell LL, Polyak K. Breast tumor heterogeneity: cancer stem cells or clonal evolution? Cell Cycle. 2007;6:2332-8.

3. Brabletz T, Jung A, Spaderna S, Hlubek F, Kirchner T. Opinion: migrating cancer stem cells - an integrated concept of malignant tumour progression. Nat Rev Cancer. 2005;5:744-9.

4. Takebe N, Harris PJ, Warren RQ, Ivy SP. Targeting cancer stem cells by inhibiting Wnt, Notch, and Hedgehog pathways. Nat Rev Clin Oncol. 2011;8:97-106.

5. Yamada R, Takahashi A, Torigoe T, Morita R, Tamura Y, Tsukahara T, Kanaseki T, Kubo T, Watarai K, Kondo T, Hirohashi $Y$, Sato N. Preferential expression of cancer/testis genes in cancer stem-like cells: proposal of a novel sub-category, cancer/testis/stem gene. Tissue Antigens. 2013;81:428-34.

6. Colombo M, Mirandola L, Platonova N, Apicella L, Basile A, Figueroa AJ, Cobos E, Chiriva-Internati $\mathrm{M}$, Chiaramonte R. Notch-directed microenvironment reprogramming in myeloma: a single path to multiple outcomes. Leukemia. 2013;27:1009-18.

7. Yin L, Velazquez OC, Liu ZJ. Notch signaling: emerging molecular targets for cancer therapy. Biochem Pharmacol. 2010;80:690-701.

8. Mumm JS, Kopan R. Notch signaling: from the outside in. Dev Biol. 2000;228:151-65.

9. Kopan R, Ilagan MX. The canonical Notch signaling pathway: unfolding the activation mechanism. Cell. 2009;137:216-33.

10. Tagami S, Okochi M, Yanagida K, Ikuta A, Fukumori A, Matsumoto N, Ishizuka-Katsura Y, Nakayama T, Itoh N, Jiang J, Nishitomi K, Kamino K, Morihara T, Hashimoto R, Tanaka T, Kudo T, Chiba S, Takeda M. Regulation of Notch signaling by dynamic changes in the precision of S3 cleavage of Notch-1. Mol Cell Biol. 2008;28:165-76.

11. Rangarajan A, Talora C, Okuyama R, Nicolas M, Mammucari C, Oh H, Aster JC, Krishna S, Metzger D, Chambon P, Miele L, Aguet M, Radtke F, Dotto GP. Notch signaling is a direct determinant of keratinocyte growth arrest and entry into differentiation. Embo J. 2001;20:3427-36.

12. Mirandola L, Apicella L, Colombo M, Yu Y, Berta DG, Platonova N, Lazzari E, Lancellotti M, Bulfamante G, Cobos E, Chiriva-Internati M, Chiaramonte R. Anti-Notch treatment prevents multiple myeloma cells localization to the bone marrow via the chemokine system CXCR4/SDF-1. Leukemia. 2013;27:1558-66.

13. Mirandola L, Chiriva-Internati M, Montagna D, Locatelli F, Zecca M, Ranzani M, Basile A, Locati M, Cobos E, Kast WM, Asselta R, Paraboschi EM, Comi P, Chiaramonte R. Notch1 regulates chemotaxis and proliferation by controlling the CC-chemokine receptors 5 and 9 in T cell acute lymphoblastic leukaemia. $J$ Pathol. 2012;226:713-22.

14. Koch U, Lehal R, Radtke F. Stem cells living with a Notch. Development. 2013;140:689-704.

15. Pannuti A, Foreman K, Rizzo P, Osipo C, Golde T, Osborne B, Miele L. Targeting Notch to target cancer stem cells. Clin Cancer Res. 2010;16:3141-52.

16. Espinoza I, Pochampally R, Xing F, Watabe K, Miele L. Notch signaling: targeting cancer stem cells and epithelial-to-mesenchymal transition. Onco Targets Ther. 2013;6:1249-59.

17. Lutolf S, Radtke F, Aguet $M$, Suter $U$, Taylor V. Notch1 is required for neuronal and glial differentiation in the cerebellum. Development. 2002;129:373-85. 
18. Wang J, Wakeman TP, Lathia JD, Hjelmeland AB, Wang XF, White RR, Rich JN, Sullenger BA. Notch promotes radioresistance of glioma stem cells. Stem Cells. 2010;28:17-28.

19. Shiras A, Chettiar ST, Shepal V, Rajendran G, Prasad GR, Shastry P. Spontaneous transformation of human adult nontumorigenic stem cells to cancer stem cells is driven by genomic instability in a human model of glioblastoma. Stem Cells. 2007;25:1478-89.

20. Fre S, Huyghe M, Mourikis P, Robine S, Louvard D, Artavanis-Tsakonas S. Notch signals control the fate of immature progenitor cells in the intestine. Nature. 2005;435:964-8.

21. Akiyoshi T, Nakamura M, Yanai K, Nagai S, Wada J, Koga K, Nakashima H, Sato N, Tanaka M, Katano M. Gamma-secretase inhibitors enhance taxane-induced mitotic arrest and apoptosis in colon cancer cells. Gastroenterology. 2008;134:131-44.

22. Miyamoto S, Rosenberg DW. Role of Notch signaling in colon homeostasis and carcinogenesis. Cancer Sci. 2011;102:1938-42.

23. van Es JH, van Gijn ME, Riccio $O$, van den Born $M$, Vooijs $M$, Begthel $H$, Cozijnsen $M$, Robine $S$, Winton DJ, Radtke F, Clevers H. Notch/gamma-secretase inhibition turns proliferative cells in intestinal crypts and adenomas into goblet cells. Nature. 2005;435:959-63.

24. Farnie G, Clarke RB. Mammary stem cells and breast cancer--role of Notch signalling. Stem Cell Rev. 2007;3:169-75.

25. Stylianou S, Clarke RB, Brennan K. Aberrant activation of notch signaling in human breast cancer. Cancer Res. 2006;66:1517-25.

26. Izrailit J, Reedijk M. Developmental pathways in breast cancer and breast tumor-initiating cells: therapeutic implications. Cancer Lett. 2012;317:115-26.

27. Rahman MT, Nakayama K, Rahman M, Katagiri H, Katagiri A, Ishibashi T, Ishikawa M, lida K, Nakayama S, Otsuki Y, Miyazaki K. Notch3 overexpression as potential therapeutic target in advanced stage chemoresistant ovarian cancer. Am J Clin Pathol. 2012;138:535-44.

27, 28. Jung SG, Kwon YD, Song JA, Back MJ, Lee SY, Lee C, Hwang YY, An HJ. Prognostic significance of Notch 3 gene expression in ovarian serous carcinoma. Cancer Sci. 2010;101:1977-83.

29. McAuliffe SM, Morgan SL, Wyant GA, Tran LT, Muto KW, Chen YS, Chin KT, Partridge JC, Poole BB, Cheng KH, Daggett J, Jr., Cullen K, Kantoff E, Hasselbatt K, Berkowitz J, Muto MG, Berkowitz RS, Aster JC, Matulonis UA, Dinulescu DM. Targeting Notch, a key pathway for ovarian cancer stem cells, sensitizes tumors to platinum therapy. Proc Natl Acad Sci U S A. 2012;109:E2939-48.

30. Bigas A, Espinosa L. Hematopoietic stem cells: to be or Notch to be. Blood. 2012;119:3226-35.

31. Liu N, Zhang J, Ji C. The emerging roles of Notch signaling in leukemia and stem cells. Biomarker Research. 2013;1:23.

32. van der Bruggen $P$, Traversari $C$, Chomez $P$, Lurquin $C$, De Plaen $E$, Van den Eynde B, Knuth $A$, Boon T. A gene encoding an antigen recognized by cytolytic $T$ lymphocytes on a human melanoma. Science. 1991;254:1643-7.

33. Chiriva-Internati M. Sperm protein 17: clinical relevance of a cancer/testis antigen, from contraception to cancer immunotherapy, and beyond. Int Rev Immunol. 2011;30:138-49.

34. Chiriva-Internati M, Ferrari R, Yu Y, Hamrick C, Gagliano N, Grizzi F, Frezza E, Jenkins MR, Hardwick F, D'Cunha N, Kast WM, Cobos E. AKAP-4: a novel cancer testis antigen for multiple myeloma: Br J Haematol. 2008 Feb;140(4):465-8. doi: 10.1111/j.1365-2141.2007.06940.x.

35. Chiriva-Internati M, Mirandola L, Kast WM, Jenkins MR, Cobos E, Cannon MJ. Understanding the cross-talk between ovarian tumors and immune cells: mechanisms for effective immunotherapies. Int Rev Immunol. 2011;30:71-86.

36. Chiriva-Internati M, Pandey A, Saba R, Kim M, Saadeh C, Lukman T, Chiaramonte R, Jenkins M, Cobos E, Jumper C, Alalawi R. Cancer testis antigens: a novel target in lung cancer. Int Rev Immunol. 2012;31:321-43.

37. Chiriva-Internati M, Wang Z, Salati E, Bumm K, Barlogie B, Lim SH. Sperm protein 17 (Sp17) is a suitable target for immunotherapy of multiple myeloma. Blood. 2002;100:961-5.

38. Chiriva-Internati M, Wang Z, Salati E, Wroblewski D, Lim SH. Successful generation of sperm protein 17 (Sp17)-specific cytotoxic T lymphocytes from normal donors: implication for tumour-specific adoptive immunotherapy following allogeneic stem cell transplantation for Sp17-positive multiple myeloma. Scand J Immunol. 2002;56:429-33. 
39. Chiriva-Internati M, Weidanz JA, Yu Y, Frezza EE, Jenkins MR, Kennedy RC, Cobos E, Kast WM. Sperm protein 17 is a suitable target for adoptive T-cell-based immunotherapy in human ovarian cancer. J Immunother. 2008;31:693-703.

40. Chiriva-Internati M, Yu Y, Mirandola L, D'Cunha N, Hardwicke F, Cannon MJ, Cobos E, Kast WM. Identification of AKAP-4 as a new cancer/testis antigen for detection and immunotherapy of prostate cancer. Prostate. 2012;72:12-23.

41. Chiriva-Internati M, Yu Y, Mirandola L, Jenkins MR, Chapman C, Cannon M, Cobos E, Kast WM. Cancer testis antigen vaccination affords long-term protection in a murine model of ovarian cancer. PLoS One. 2010;5:0010471.

42. Mirandola L, Yu Y, Jenkins MR, Chiaramonte R, Cobos E, John CM, Chiriva-Internati M. Tracking human multiple myeloma xenografts in NOD-Rag-1/IL-2 receptor gamma chain-null mice with the novel biomarker AKAP-4. BMC Cancer. 2011;11:1471-2407.

43. Pandey A, Kurup A, Shrivastava A, Radhi S, Nguyen DD, Arentz C, D'Chuna N, Hardwick F, D'Souza MJ, Jenkins M, Grizzi F, Kast WM, Cobos E, Rahman R, Chiriva-Internati M, Chiaramonte R, Platonova N. Cancer testes antigens in breast cancer: biological role, regulation, and therapeutic applicability. Int Rev Immunol. 2012;31:302-20.

44. Sigalotti L, Fratta E, Coral S, et al. Intratumor heterogeneity of cancer/testis antigens expression in human cutaneous melanoma is methylation-regulated and functionally reverted by 5-aza-2'deoxycytidine. Cancer Res 64, no. 24 (2004): 9167-9171.

45. Simpson AJ, Caballero OL, Jungbluth A, Chen YT, Old L. Cancer/testis antigens, gametogenesis and cancer. Nat Rev Cancer. 2005;5:615-25.

46. Ait-Tahar K, Liggins AP, Collins GP, Campbell A, Barnardo M, Lawrie C, Moir D, Hatton C, Banham AH, Pulford K. Cytolytic T-cell response to the PASD1 cancer testis antigen in patients with diffuse large Bcell lymphoma. Br J Haematol. 2009;146:396-407.

47. Caballero OL, Chen Y-T. Cancer/testis (CT) antigens: Potential targets for immunotherapy. Cancer Science. 2009;100:2014-21.

48. Hunder M,, Herschel W, Jianhong $C$, et al. Treatment of metastatic melanoma with autologous CD4+ T cells against NY-ESO-1. NEJM 358: 2698-2703,2008.

49. Sadanaga N, Hideki N, Kohjiro M, et al. Dendritic cell vaccination with MAGE peptide is a novel therapeutic approach for gastrointestinal carcinomas. Clin Cancer Res 7: 2001, 2277-2284.

50. Chiriva-Internati M, Cobos E, Kast WM. Advances in immunotherapy of multiple myeloma: from the discovery of tumor-associated antigens to clinical trials. Int Rev Immunol. 2007;26:197-222.

51. Chiriva-Internati M, Gagliano N, Donetti E, Costa F, Grizzi F, Franceschini B, Albani E, Levi-Setti PE, Gioia $M$, Jenkins $M$, Cobos E, Kast WM. Sperm protein 17 is expressed in the sperm fibrous sheath. J Transl Med. 2009;7:1479-5876.

52. Chiriva-Internati M, Mirandola L, Yu Y, Jenkins MR, Gornati R, Bernardini G, Gioia M, Chiaramonte R, Cannon MJ, Kast WM, Cobos E. Cancer testis antigen, ropporin, is a potential target for multiple myeloma immunotherapy. J Immunother. 2011;34:490-9.

53. Dadabayev AR, Wang Z, Zhang Y, Zhang J, Robinson WR, Lim SH. Cancer immunotherapy targeting Sp17: when should the laboratory findings be translated to the clinics? Am J Hematol. 2005;80:6-11.

54. Costa FF, Le Blanc K, Brodin B. Concise review: cancer/testis antigens, stem cells, and cancer. Stem Cells. 2007;25:707-11.

55. Cronwright G, Le Blanc K, Gotherstrom C, Darcy P, Ehnman M, Brodin B. Cancer/testis antigen expression in human mesenchymal stem cells: down-regulation of SSX impairs cell migration and matrix metalloproteinase 2 expression. Cancer Res. 2005;65:2207-15.

56. Serakinci N, Guldberg P, Burns IS, Abdallah B, Schrodder H, Jensen T, Kassem M. Adult human mesenchymal stem cell as a target for neoplastic transformation. Oncogene. 2004;23:5095-8.

57. Gjerstorff M, Burns JS, Nielsen O, Kassem M, Ditzel H. Epigenetic modulation of cancer-germline antigen gene expression in tumorigenic human mesenchymal stem cells: implications for cancer therapy. Am J Pathol. 2009;175:314-23.

58. Beier D, Hau P, Proescholdt M, et al. CD133+ and CD133- glioblastoma-derived cancer stem cells show differential growth characteristics and molecular profiles. Cancer Res 67, no. 9 (2007): 4010-4015. 
59. Yawata T, Nakai E, Park KC, Chihara T, Kumazawa A, Toyonaga S, Masahira T, Nakabayashi H, Kaji T, Shimizu K. Enhanced expression of cancer testis antigen genes in glioma stem cells. Mol Carcinog. 2010;49:532-44.

60. Atanackovic D, Hildebrandt Y, Jadczak A, Cao Y, Luetkens T, Meyer S, Kobold S, Bartels K, Pabst C, Lajmi N, Gordic M, Stahl T, Zander AR, Bokemeyer C, Kroger N. Cancer-testis antigens MAGE-C1/CT7 and MAGE-A3 promote the survival of multiple myeloma cells. Haematologica. 2010;95:785-93.

61. Scanlan MJ, Simpson AJ, Old LJ. The cancer/testis genes: review, standardization, and commentary. Cancer Immun. 2004;4:1.

62. Old LJ. Cancer/testis (CT) antigens - a new link between gametogenesis and cancer: Cancer Immun. 2001 Mar 30;1:1.

63. Gurchot C. The trophoblast theory of cancer (John Beard, 1857-1924) revisited. Oncology. 1975;31:310-33.

64. Andrade VC, Vettore AL, Felix RS, Almeida MS, Carvalho F, Oliveira JS, Chauffaille ML, Andriolo A, Caballero OL, Zago MA, Colleoni GW. Prognostic impact of cancer/testis antigen expression in advanced stage multiple myeloma patients. Cancer Immun. 2008;8:2.

65. Atanackovic D, Luetkens T, Hildebrandt Y, Arfsten J, Bartels K, Horn C, Stahl T, Cao Y, Zander AR, Bokemeyer C, Kroger N. Longitudinal analysis and prognostic effect of cancer-testis antigen expression in multiple myeloma. Clin Cancer Res. 2009;15:1343-52.

66. Condomines M, Hose D, Reme T, Requirand G, Hundemer M, Schoenhals M, Goldschmidt H, Klein B. Gene expression profiling and real-time PCR analyses identify novel potential cancer-testis antigens in multiple myeloma. J Immunol. 2009;183:832-40.

67. Pabst C, Zustin J, Jacobsen F, Luetkens T, Kroger N, Schilling G, Bokemeyer C, Sauter G, Atanackovic D, Marx A. Expression and prognostic relevance of MAGE-C1/CT7 and MAGE-C2/CT10 in osteolytic lesions of patients with multiple myeloma. Exp Mol Pathol. 2010.

68. Jungbluth, Achim A., Scott Ely, Maurizio DiLiberto, Ruben Niesvizky, Barbara Williamson, Denise Frosina, Yao-Tseng Chen et al. "The cancer-testis antigens CT7 (MAGE-C1) and MAGE-A3/6 are commonly expressed in multiple myeloma and correlate with plasma-cell proliferation." Blood 106, no. 1 (2005): 167174.

69. Dhodapkar, Madhav V., Keren Osman, Julie Teruya-Feldstein, Daniel Filippa, Cyrus V. Hedvat, Kristin Iversen, Denise Kolb et al. "Expression of cancer/testis (CT) antigens MAGE-A1, MAGE-A3, MAGEA4, CT-7, and NY-ESO-1 in malignant gammopathies is heterogeneous and correlates with site, stage and risk status of disease." Cancer Immun 3, no. 9 (2003): 9.

70. Jundt F, Probsting KS, Anagnostopoulos I, Muehlinghaus G, Chatterjee M, Mathas S, Bargou RC, Manz R, Stein H, Dorken B. Jagged1-induced Notch signaling drives proliferation of multiple myeloma cells. Blood. 2004;103:3511-5.

71. Schwarzer R, Kaiser M, Acikgoez O, Heider U, Mathas S, Preissner R, Sezer O, Doerken B, Jundt F. Notch inhibition blocks multiple myeloma cell-induced osteoclast activation. Leukemia. 2008;22:2273-7.

72. Chen-Kiang S. Cell-cycle control of plasma cell differentiation and tumorigenesis. Immunol Rev. 2003;194:39-47.

73. Nefedova Y, Cheng P, Alsina M, Dalton WS, Gabrilovich DI. Involvement of Notch-1 signaling in bone marrow stroma-mediated de novo drug resistance of myeloma and other malignant lymphoid cell lines. Blood. 2004;103:3503-10.

74. Wen Y, Richardson RT, Widgren EE, O'Rand MG. Characterization of Sp17: a ubiquitous three domain protein that binds heparin. Biochem J. 2001;357:25-31.

75. Newell AE, Fiedler SE, Ruan JM, Pan J, Wang PJ, Deininger J, Corless CL, Carr DW. Protein kinase A RII-like (R2D2) proteins exhibit differential localization and AKAP interaction. Cell Motil Cytoskeleton. 2008;65:539-52.

76. Wen Y, Richardson RT, O'Rand M G. Processing of the sperm protein Sp17 during the acrosome reaction and characterization as a calmodulin binding protein. Dev Biol. 1999;206:113-22.

77. Lea IA, Widgren EE, O'Rand MG. Association of sperm protein 17 with A-kinase anchoring protein 3 in flagella. Reprod Biol Endocrinol. England2004. p. 57. 
78. Hedrick ED, Agarwal E, Leiphrakpam PD, Haferbier KL, Brattain MG, Chowdhury S. Differential PKA activation and AKAP association determines cell fate in cancer cells. J Mol Signal. 2013;8:10.

79. Weber JM, Forsythe SR, Christianson CA, Frisch BJ, Gigliotti BJ, Jordan CT, Milner LA, Guzman ML, Calvi LM. Parathyroid hormone stimulates expression of the Notch ligand Jagged1 in osteoblastic cells. Bone. 2006;39:485-93.

80. Yurugi-Kobayashi T, Itoh H, Schroeder T, Nakano A, Narazaki G, Kita F, Yanagi K, Hiraoka-Kanie M, Inoue E, Ara T, Nagasawa T, Just U, Nakao K, Nishikawa S, Yamashita JK. Adrenomedullin/cyclic AMP pathway induces Notch activation and differentiation of arterial endothelial cells from vascular progenitors. Arterioscler Thromb Vasc Biol. 2006;26:1977-84.

81. Huangfu D, Liu A, Rakeman AS, Murcia NS, Niswander L, Anderson KV. Hedgehog signalling in the mouse requires intraflagellar transport proteins. Nature 2003. p. 83-7.

82. Lacy, H. Marie, and Ralph D. Sanderson. "Sperm protein 17 is expressed on normal and malignant lymphocytes and promotes heparan sulfate-mediated cell-cell adhesion." Blood 98, no. 7 (2001): 21602165.

83. Li, Fang-qiu, Yan-ling Han, Qun Liu, Bo Wu, Wen-bin Huang, and Su-yun Zeng. "Overexpression of human sperm protein 17 increases migration and decreases the chemosensitivity of human epithelial ovarian cancer cells." BMC cancer 9, no. 1 (2009): 323.

.84. Ruben JM, Visser LL, Bontkes HJ, Westers TM, Ossenkoppele GJ, de Gruijl TD, van de Loosdrecht AA. Targeting the acute myeloid leukemic stem cell compartment by enhancing tumor cell-based vaccines. Immunotherapy. 2013;5:859-68.

85. Jin L, Hope KJ, Zhai Q, Smadja-Joffe F, Dick JE. Targeting of CD44 eradicates human acute myeloid leukemic stem cells. Nat Med. 2006;12:1167-74.

86. Rao M, Chinnasamy N, Hong JA, Zhang Y, Zhang M, Xi S, Liu F, Marquez VE, Morgan RA, Schrump DS. Inhibition of histone lysine methylation enhances cancer-testis antigen expression in lung cancer cells: implications for adoptive immunotherapy of cancer. Cancer Res. 2011;71:4192-204.

87. James SR, Cedeno CD, Sharma A, Zhang W, Mohler JL, Odunsi K, Wilson EM, Karpf AR. DNA methylation and nucleosome occupancy regulate the cancer germline antigen gene MAGEA11. Epigenetics. 2013;8:8.

88. Kim KM, Song MH, Kim MJ, Daudi S, Miliotto A, Old L, Odunsi K, Lee SY. A novel cancer/testis antigen KP-OVA-52 identified by SEREX in human ovarian cancer is regulated by DNA methylation. Int J Oncol. 2012;41:1139-47.

89. Kim R, Kulkarni P, Hannenhalli S. Derepression of Cancer/testis antigens in cancer is associated with distinct patterns of DNA hypomethylation. BMC Cancer. 2013;13:1471-2407.

90. Dominguez M. Interplay between Notch Signaling and Epigenetic Silencers in Cancer. Cancer Research. 2006;66:8931-4.

91. Hu W, Lu C, Dong HH, Huang J, Shen DY, Stone RL, Nick AM, Shahzad MM, Mora E, Jennings NB, Lee SJ, Roh JW, Matsuo K, Nishimura M, Goodman BW, Jaffe RB, Langley RR, Deavers MT, Lopez-Berestein G, Coleman RL, Sood AK. Biological roles of the Delta family Notch ligand DIl4 in tumor and endothelial cells in ovarian cancer. Cancer Res. 2011;71:6030-9.

92. Strosberg JR, Yeatman T, Weber J, Coppola D, Schell MJ, Han G, Almhanna K, Kim R, Valone T, Jump H, Sullivan D. A phase II study of RO4929097 in metastatic colorectal cancer. Eur J Cancer. 2012;48:9971003.

93. Wong GT, Manfra D, Poulet FM, Zhang $Q$, Josien $H$, Bara $T$, Engstrom L, Pinzon-Ortiz M, Fine JS, Lee HJ, Zhang L, Higgins GA, Parker EM. Chronic treatment with the gamma-secretase inhibitor LY-411,575 inhibits beta-amyloid peptide production and alters lymphopoiesis and intestinal cell differentiation. J Biol Chem. 2004;279:12876-82. 
94. Wu Y, Cain-Hom C, Choy L, Hagenbeek TJ, de Leon GP, Chen Y, Finkle D, Venook R, Wu X, Ridgway J, Schahin-Reed D, Dow GJ, Shelton A, Stawicki S, Watts RJ, Zhang J, Choy R, Howard P, Kadyk L, Yan M, Zha J, Callahan CA, Hymowitz SG, Siebel CW. Therapeutic antibody targeting of individual Notch receptors. Nature. 2010;464:1052-7.

95. Aste-Amezaga $\mathrm{M}$, Zhang N, Lineberger JE, Arnold BA, Toner TJ, Gu M, Huang L, Vitelli S, Vo KT, Haytko P, Zhao JZ, Baleydier F, L'Heureux S, Wang H, Gordon WR, Thoryk E, Andrawes MB, Tiyanont K, Stegmaier K, Roti G, Ross KN, Franlin LL, Wang F, Chastain M, Bett AJ, Audoly LP, Aster JC, Blacklow SC, Huber HE. Characterization of Notch1 antibodies that inhibit signaling of both normal and mutated Notch1 receptors. PLoS One. 2010;5.

96. Akers SN, Odunsi K, Karpf AR. Regulation of cancer germline antigen gene expression: implications for cancer immunotherapy. Future Oncol. 2010;6:717-32.

\section{Figure legends}

Figure 1. Possible role of CTA signaling in Notch activation in MM. CTA (i.e. SP17, AKAP4) could directly enhance Notch activation by stabilizing the Notch intracellular domain (1), or they could activate PKA through cAMP increase, which may lead to Notch ligand Jagged12overexpression, eventually resulting in Notch activation and consequent MM TIC self-renewal. 


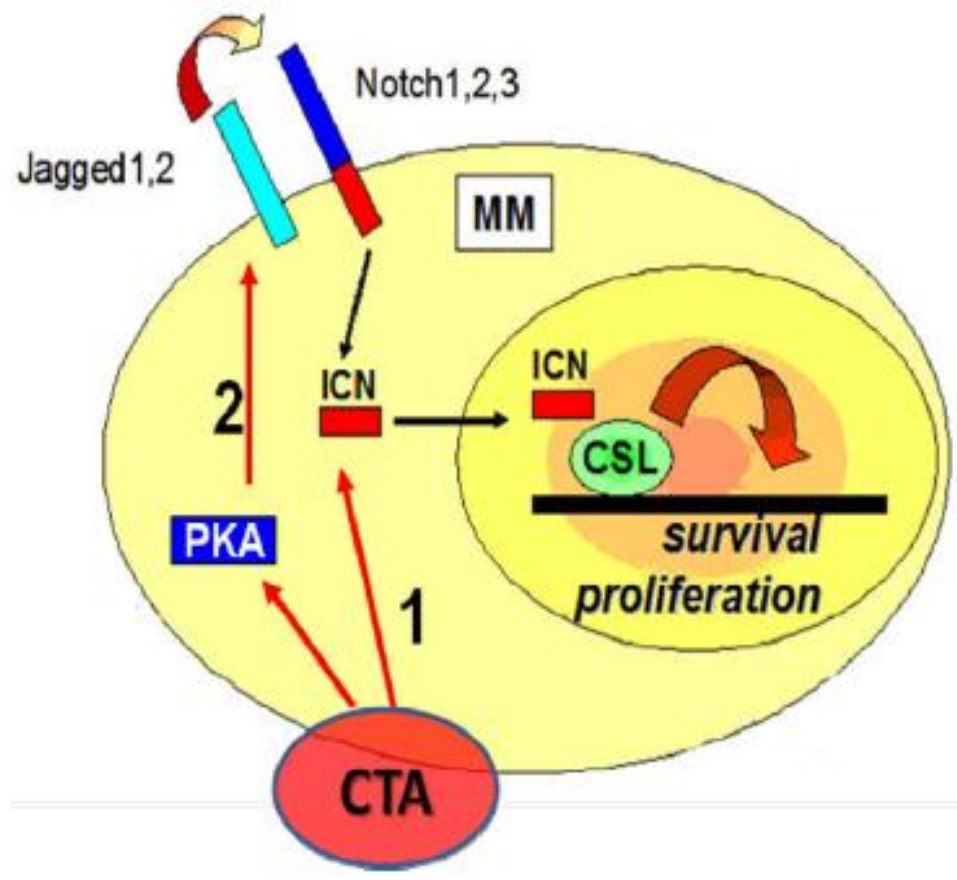

